\title{
A trajetória do núcleo de Pesquisa em História do IFCH/UFRGS
}

Lizete Oliveira Kummer*

O Núcleo de Pesquisa em História (NPH) está vinculado ao Departamento de História e ao Programa de Pós-Graduação em História do Instituto de Filosofia e Ciências Humanas (IFCH) da Universidade Federal do Rio Grande do Sul e constitui-se em um espaço de convivência entre a pesquisa e a documentação na área do conhecimento histórico. Atualmente a equipe de trabalho é composta pelos historiadores Francisco Carvalho Jr. e Lizete Oliveira Kummer e pela socióloga Rosemary F. Brum, sob a coordenação do professor Benito Schmidt. Os fundos documentais e a biblioteca do NPH têm sido consultados por pesquisadores das ciências humanas e alunos de graduação e pós-graduação. Além da produção de pesquisas e organização de coleções de documentos,

\footnotetext{
* Lizete Oliveira Kummer é historiadora do Núcleo de Pesquisa em História do IFCH/UFRGS, Mestre em História pela UFRGS e doutoranda no PPG História/ UFRGS.
}

Anos 90, Porto Alegre, v. 13, n. 23/24, p.77-83, jan./dez. 2006 


\section{A trajetória do Núcleo de Pesquisa em História...}

diversas atividades têm marcado a sua trajetória: promoção de cursos, palestras e debates; participação em exposições didáticas e comemorativas; colaboração com as disciplinas de Técnica de Pesquisa do curso de graduação em História, entre outras.

A origem do NPH está ligada ao projeto de pesquisa $O$ processo de industrialização no Rio Grande do Sul (1889-1945), desenvolvido por professores do Departamento de História a partir de 1982, com o apoio da Financiadora de Estudos e Projetos (FINEP), do Conselho Nacional de Pesquisa (CNPq) e da Fundação de Amparo à Pesquisa do Estado do Rio Grande do Sul (FAPERGS). Esse projeto realizou um amplo levantamento da documentação sobre o tema e o seu acervo passou a integrar o NPH. O Núcleo também incorporou o acervo do extinto Gabinete de Pesquisa de História do Rio Grande do Sul, criado no IFCH em 1973, por iniciativa do professor Dante de Laytano, com o objetivo de subsidiar pesquisas na área da história regional. O Gabinete reuniu bibliografia sobre o Rio Grande do Sul, publicou obras e um periódico, o Boletim, que teve seu primeiro número editado em 20 de setembro de 1973.

A equipe do projeto de pesquisa UFRGS-FINEP incluía os professores Adolar Koch, Heloísa J. Reichel, Sandra J. Pesavento, Sílvia R. F. Petersen e um grupo de pesquisadores graduados em História, que publicaram o Guia preliminar de fontes para o estudo do processo de industrialização no Rio Grande do Sul (1889-1945). O acervo resultante da pesquisa inclui um fichário com a localização das fontes e cópias de diversos documentos sobre a indústria e o movimento operário, como livros de atas, boletins e estatutos de associações, jornais operários e muitos outros. Esse conjunto de documentos microfilmados ou fotocopiados vem sendo consultado por diversos pesquisadores, especialmente como subsídio a teses, dissertações e monografias, e o acesso a suas informações é facilitado pela estruturação de um banco de dados. O acervo documental e bibliográfico do NPH sobre trabalho, indústria e 
movimento operário vem sendo ampliado com novas fotocópias, microfilmes e publicações doadas por pesquisadores do tema ou adquiridas. A título de exemplo citamos a incorporação recente de uma coleção de jornais e documentos avulsos sobre a história do PCB, do acervo particular do pesquisador João Batista Marçal.

Em 2005, foi transferida para o NPH parte da documentação do extinto Centro de Documentação do Sindicalismo (CDS), destruído por um incêndio em 1993. O CDS integrava o Instituto de Estudos Sociais, Políticos e Econômicos da Pontifícia Universidade Católica do Rio Grande do Sul (PUCRS) e foi incorporado ao Programa de Pós-Graduação em Sociologia do IFCH/UFRGS em 1987 (Leite, 1993, p.86). Encontram-se à disposição para consulta uma expressiva quantidade de jornais da imprensa alternativa a partir da década de sessenta, como Opinião, Pasquim, Movimento e outros, publicações periódicas de sindicatos, recortes de jornais sobre sindicalismo e movimentos sociais e outras fontes sobre o tema.

O esforço do Núcleo de Pesquisa em História no sentido de preservar a memória da história do trabalho no Rio Grande do Sul conta ainda com o episódio do resgate de documentos da Delegacia Regional do Trabalho relativos ao período de 1930 a 1968. A documentação, contendo dados de identificação dos trabalhadores, estava se deteriorando e a equipe do NPH providenciou a sua transferência para o IFCH. Os documentos foram organizados e doados para o Núcleo de Documentação Histórica da Universidade Federal de Pelotas.

O NPH também organizou o arquivo pessoal de Edmundo Gardolinski, que havia sido doado à UFRGS pela família do titular, após o seu falecimento; a organização, em 1991/1992, contou com o auxílio da FAPERGS. O engenheiro Edmundo Gardolinski foi um dos responsáveis pela criação da Vila do IAPI, em Porto Alegre, e dedicou-se ao estudo da história da colonização e imigração polonesa. Visitou pessoalmente núcleos de imigrantes 


\section{A trajetória do Núcleo de Pesquisa em História...}

poloneses no Rio Grande do Sul e em outros estados, realizando entrevistas, pesquisando e coletando a documentação local. O arquivo, que se encontra à disposição para consulta no NPH, é constituído por diversos tipos de documentos, inclusive fotografias, recortes de jornais e parte da biblioteca do titular.

A produção de pesquisas e a reflexão teórica sobre a história oral integram a trajetória do NPH através do Laboratório de História Oral e outras narrativas (LHO). As atividades do grupo iniciaram com o depoimento de Eloy Martins, líder sindical e militante comunista, para a professora Maria Luiza Martini e o historiador Francisco Carvalho Jr. (Martins, 1989), e prosseguiram com o depoimento da também militante comunista e operária Julieta Battistioli, inserindo-se na linha de pesquisa Acervo de depoimentos de antigos operários e militantes comunistas. Posteriormente, integraram-se ao grupo as professoras Ieda Gutfreind e Heloísa J. Reichel, tendo como resultado a constituição do projeto Banco de depoimentos, de 1991, com duas linhas de pesquisa: operários sindicalistas e militantes políticos; historiadores gaúchos. O LHO participou, no período de 1998 a 2000, do projeto interinstitucional História oral, uma narrativa interdisciplinar, em parceria com a Universidade do Vale do Rio dos Sinos (UNISINOS) e o Instituto Cultural Judaico Marc Chagall (ICJMC), com o apoio da FAPERGS, sob a coordenação da professora Ieda Gutfreind, na época ligada à UNISINOS e ao ICJMC. Os integrantes do LHO realizam reuniões de estudo, ministram cursos e publicam artigos sobre a metodologia da história oral e suas experiências de pesquisa ${ }^{1}$. Mais recentemente, pesquisas conduzidas de forma autônoma por docentes e pósgraduandos, mas com discussão teórica coletiva, trataram de temas como meninos de rua, grupos étnicos, jovens operários.

A equipe do NPH vem participando de atividades que dizem respeito à necessidade e importância de preservar a memória da UFRGS, no sentido de conservar e organizar a documentação produzida pela Universidade. Em 1998, sob a coordenação da 
professora Regina Weber, o NPH participou, ao lado do Museu Universitário, do projeto Levantamento e reconhecimento dos acervos documentais da UFRGS, que contou também com o apoio da FAPERGS. A equipe do projeto visitou 28 acervos de unidades e órgãos da UFRGS com o objetivo de avaliar a organização e estado de conservação dos documentos que, produzidos pela Universidade, não se encontravam mais em uso administrativo corrente. ${ }^{2}$ O projeto História do IFCH/UFRGS: fontes para pesquisas da instituição e seus intelectuais, desenvolvido em 2001/2002, um desdobramento do anterior, também apoiado pela FAPERGS, voltou-se para a preservação de documentos produzidos pelo IFCH. A equipe do projeto selecionou e organizou um conjunto significativo de documentos, produzindo um inventário do acervo que pode ser consultado no NPH.

O NPH possui uma pequena biblioteca de apoio relacionada a seus acervos documentais e linhas de pesquisa, onde destacamos a bibliografia referente à história da indústria e trabalho; etnias e etnicidade; memória e história oral e diversos volumes das coletâneas de documentos do período colonial editadas pela Biblioteca Nacional. A documentação sobre o Brasil colonial recolhida pelo Projeto Resgate, que microfilmou e digitalizou o acervo do Arquivo Histórico Ultramarino de Lisboa, encontra-se também disponível no NPH. Os documentos, como cartas régias, decretos, provisões, alvarás, portarias, requerimentos, cartas e ofícios, consultas e pareceres, cartas patentes e passaportes, demonstram as relações político-administrativas entre a metrópole e as capitanias. Também pode ser consultado o micro-acervo $A$ Capela Positivista, organizado por Elizabete Leal e Paulo Pezat, que contém, entre outras fontes, publicações da Igreja e Apostolado Positivista do Brasil de 1881 a 1981 e publicações do núcleo sulrio-grandense de positivistas religiosos (1893-1957).

A trajetória do Núcleo de Pesquisa em História é o resultado do trabalho conjunto dos pesquisadores que ainda hoje integram a 


\section{A trajetória do Núcleo de Pesquisa em História...}

sua equipe, assim como do de diversos outros que participaram de sua história. Tem contado com a colaboração decisiva de professores do IFCH e do PPG em História e de muitos estudantes que atuaram como bolsistas nas suas atividades e projetos.

O NPH possui um sítio com informações sobre seu acervo: www6.ufrgs.br/nph e está localizado na sala 214 do prédio 43311 do Campus do Vale. Contatos pelo telefone 33086631 ou e-mail: nph@ufrgs.br.

Recebido em 30/05/2006.

Autora convidada.

\section{Notas}

\footnotetext{
${ }^{1}$ Parte dos resultados do trabalho da equipe encontra-se publicada: Dossiê, 1996/ 1997; Marques, 1997; Reichel, 1994.

${ }^{2}$ Um resumo dos resultados da pesquisa e de iniciativas anteriores de preservar a memória da UFRGS encontra-se em Weber, Heinen, Kummer, 2001/2002.
}

\section{Referências}

DOSSIÊ História Oral. Humanas: revista do Instituto de Filosofia e Ciências Humanas da UFRGS, Porto Alegre, v.19/20, n.1/2, p.95-216, 1996/1997.

LEITE, Luiz Osvaldo. Instituto de Filosofia e Ciências Humanas: subsídios históricos. In: 50 anos da Faculdade de Filosofia: publicação comemorativa. Organização: Comissão 50 anos. Porto Alegre: Universidade Federal do Rio Grande do Sul, 1993.

MADURO, Acácia Maria Ramires et al. Guia preliminar de fontes para o estudo do processo de industrialização no Rio Grande do Sul (1889-1945). Porto Alegre: Ed. UFRGS/ Fundação de Economia e Estatística, 1986.

MARQUES, Miguel. Conhecendo Miguel Marques: o KGB. Porto Alegre: Secretaria Municipal de Cultura/ EU, 1987.

Anos 90, Porto Alegre, v. 13, n. 23/24, p.77-83, jan./dez. 2006 


\section{Lizete Oliveira Kummer}

MARTINS, Eloy. Um depoimento político. Porto Alegre: Pallotti, 1989.

REICHEL, Heloísa J. (coord.) et al. Vida e trabalho num bairro fabril: depoimentos. Anos 90, Porto Alegre, n.2, p.183-197, maio 1994.

WEBER, Regina; HEINEN, Nívea; KUMMER, Lizete. Acervos documentais da UFRGS: riqueza e desorganização. Anos 90, Porto Alegre, n.15, p.143-149, $2001 / 2002$. 